\title{
Atypical Athletic Corporeality and Clinical Embodied Deviance: A Case Study of Dutee Chand
}

\author{
Isha Malhotra ${ }^{1} \&$ Raj Thakur ${ }^{2}$ \\ ${ }^{1}$ Assistant Professor and Head in the School of Languages and Literature, Faculty of Humanities \\ and Social Sciences at Shri Mata Vaishno Devi University, UT of J\&K, India. \\ Email: isha.malhotra@smvdu.ac.in \\ ${ }^{2}$ Assistant Professor in the Department of English at Central University of Jammu, UT of J\&K, \\ India. Email: raj.eng@cujammu.ac.in
}

\begin{abstract}
The paper outlines the politics of gendered athleticism appropriated and instrumentalised through the medico-juridical apparatus of the sports governing bodies. The biomedical discourse governing the atypical athletic body and the embodied nature of its pathologised deviancy is drawn through the critical reflection of athletic regulatory bodies' testing regimes and policies. It is through the detailed analysis of the Indian sprinter Dutee Chand's case that one of many confounding disqualification charges and trials of hyperandrogenism against athletes with differences of sex development (DSD's) is foregrounded. Drawing on the critical scholarship of gender theorists and activists, the legitimacy of the stipulated biological mechanism of the testosterone as a regulatory performance index in female elite sport is contested and problematized. Pertinent here is Dutee Chands's narrative of trial and triumph that destabilises the reductive embodiments of sex institutionalised in and beyond the sporting track. Significantly, the paper also delineates the premises of the constitutive exclusionary and arbitrary regulatory regimes propounded by the athletic governing bodies like International Association of Athletics Federations (IAAF) and the International Olympic Committee (IOC). These concerns border on the geopolitics of race and nation framing the normative, prescriptive and reserved rights of femininity, able-bodiedness and heteronormativity in international women's elite sport.
\end{abstract}

Keywords: DSDs, sport, gender, medicine, sex testing, regulation, heteronormativity

\section{Introduction}

This paper critically examines the socially controlling biomedical discourse and its invasive interventions in the realm of sportspersons with differences of sex development (DSDs) through the case study of the Indian sprinter, Dutee Chand. The chronology of various sex tests undergone by the athletes with DDSs are placed within the biomedical discourse of gender and sexuality. What is brought under purview is the objective scientific claims of western medicine based on the empiricist logic of humanism. Debunking the assumptions, the paper infers that the "clinical gaze" of the medical practitioners is loaded with cultural meanings and biases which in turn tamper the empirical observation (Foucault, 2003). The entire logic of establishing medical science in humanist empiricism is to understand and categorise bodies within the binaries of either normal 
or pathologised. The clinical studies uses measures of sameness as normalised as opposed to differences which are seen as deviant and hence subversive or transgressive. The predominant fallacy of these empirical claims "is a neglect of a recognition of the sociocultural function of the categories of normal and pathological, and medical participation in the way these terms come to mean in lay society, and their sedimentation in pre-conscious practices of perception" (Murray, 2007, p.361). The competing and contradictory medical and scientific mechanisms are adopted by the athletic governing bodies like International Association of Athletics Federations (IAAF) and the International Olympic Committee (IOC) to ascertain atypical athletic corporeality of intersex sportspersons through various sex tests and regulations, notably "nude parades, the Barr body test, the Stockholm Consensus, and the Hyperandrogenism Regulations" (Rupert, 2011). The medico-legal custodians of these sports bodies envision these as deviant bodies within a binary framework, thus, labelling them as pathological and implicitly promoting heteronormativity.

The sex-segregation in sports has predated on two dominant heteronormative constructs: one being the dichotomous nature of sex and gender viz. male/female or man/woman and the other being the inherent biological advantage of former over latter in terms of sporting prowess. There have been contentious efforts in sports history to define femaleness. The primary reason for this exercise was to control women's participation in sports which was ostensibly a male preserve and threatened the essentialist femininity of women and conventional sex and gender roles (Dunning, 1986). The anxiety of the male-centric sports governing bodies like the IAAF, the International Olympic Committee (IOC) aggravated with increased women participation in international athletics in the 1920s. The critics pronounced these events as "profoundly unnatural" apprehending female athletes will develop wholly masculine physique and behaviour traits" (Rand, 1929 , p. 194). However, the growing popularity of women track and field events made them relent (Leigh and Bonin, 1977). From the 1930s onwards, the sports authorities in the name of fair play have constantly pitched in biomedical intervention through various sex tests to validate their ideology of sex-segregation. Ensuing in the early 1930s and 40s, the female athletic bodies were subjected to institutionalised biomedical regulations. These tests underwent many procedural and political changes post 1950s and a close scrutiny of these highlight the arbitrary nature of these testing policies. Interestingly, Fausto-Sterling (1992) depicts the confounding parallel epistemological claims, suggesting how research studies in endocrinology, genetics and forensic psychology, anthropology and sociology started perceiving gender identities as fluid and complex which could not be relegated to binaries.

Since the first half of the twentieth century and till date with certain regulations, the athletes' performative anxiety on the part of IOC and IAAF is queered through appearances, chromosomes and testosterone levels. These tests have far-reaching consequences on athletes with differences of sex development (DSDs). Such perplexing policies remain "stubbornly committed to a binary model of embodied difference" (Pape, p.2). Rittel and Webber (1973) opined that the biomedical researchers and policymakers who formulate such regulatory policies erroneously assumed that "they can solve problems in the ways that scientists can solve their problems. The error has been a serious one" (p. 160). The lives of gendered athletes are constructed, conceptualised and regulated through the gendered discourse of sporting codes. A case in point here becomes the Indian sprinter Dutee Chand's intersexed athletic body put on medico-legal trial and reduced to "partial instantiation, represented in terms of hormones alone 
and measures of testosterone in particular." (Berg and Akrich, 2004, p. 4). She was disqualified to compete in the women category as she was diagnosed as hyperandrogenic following which she was given two options: either to drop out of sport or to undergo medical intervention. Boldly, she refused both the options. Instead, on expert advice by her legal team, she chose to appeal against her disqualification. Her appeal stands as a direct affront to the institutional mechanisms that rationalise the medicalization of corporeal difference and normalisation technique. Her case poses a challenge to the discourse of "western biomedicine" (Kessler, 1990, p.33-38) which appears to be deeply grounded in hegemonical enterprise of whiteness, racialization, heteronormativity and able-bodiedness.

\section{Methodology}

The study of the instrumentalised intersex athletes' body and its debilitating consequences is informed by interdisciplinary and intersectional approaches. The sporting bodies regulated regimes of scientific truth, validity and eligibility is primarily conceptualised through the Foucauldian biomedical discourses on sexuality. Michel Foucault in his foundational work, The Birth of the Clinic (1973), foregrounds the productive nature of powers as new forms of knowledge and disciplinary strategies that emerge towards the end of the eighteenth century. Foucault (1973) delineates how through "scientific" knowledge, precision and objectivity, the medical profession gained prestige (Foucault, 1973). Its classificatory schema of disease through the "totalizing" frames of "normal" and the "deviant" marked the body as a site of subjugation. Consequently, the disciplinary "clinical gaze" was utilised to neutralise any deviant pattern (Foucault, 1973, p. 108). Foucault (2003) claims that the predominant function of the "clinical gaze" was to "record and totalize" "perceive" and make disease intelligible. (p. 149) However, the claim that medicine is based on detached distance is a myth as Foucault notes that the clinical gaze of the medical practitioner is coloured by dominant modes of perception. Foucault contends:

The clinical gaze is not that of an intellectual eye that is able to perceive the unalterable purity of essences beneath phenomena. It is a gaze of concrete sensibility, a gaze that travels from body to body, and whose trajectory is situated in the space of sensible manifestation. (2003, p. 148)

The deterministic sexuality being the key source of power here, it conflates through the production of knowledge and its "success is proportional to its ability to hide its own mechanism" (Foucault, 1980, p. 86). He theorizes that since the nineteenth century, medicine "was regulated more in accordance with normality than with health", and consequently, the biomedical discourse began to be constructed around the binaries of the normal and the pathological (p. 34-35). Retreading Foucault, Terry and Urla (1995), postulated the concept of "embodied deviance", defined as the term given to "the scientific and popular postulate that the bodies of subjects classified as deviant are essentially marked in some recognisable fashion" (p. 2). Alcoff's work validates that there is no such thing as "simple perception" and further establishes perception as a knowledge-making process which constitutes "identity and difference, normalcy and pathology" (Murray, 2007, p. 362). The doctor's gaze is constantly structured by the culturally constructed understanding of embodiment, normalcy and pathology during examination of the deviant bodies. 
Critical interventions from Anne Fausto Sterling, Katrina Karkazis and Suzanne J. Kessler are drawn upon to reconfigure the politics of difference by reconceptualising the heteronormative assumptions about sex, gender, sexuality and embodiments. These writers have made considerable interjections on social and medical handling of the people with intersex conditions. Most significantly, these attend to the matters of "bodies as inextricable from biopolitical processes that position human anatomy and morphology as objects of regulation" (Rubin, 2017, p.50). Fausto-Sterling (2000) grounds how the biomedical examination of intersex is not an absolute means but a conducive factor in standardisation of the cultural norm. Critically envisioning feminist theory and history of science, she argues against the dualism of nature/culture, sex/gender, male/female, heterosexuality/homosexuality propounded by the bioscientific mechanisms like genetics, neuroscience, and endocrinology. She stresses how the body as a bio entity is too complex to be left only to scientists, stating "the more we look for a simple physical basis for 'sex' the more it becomes clear that 'sex' is not a purely physical category" ( $p$. 4). Citing Fausto-Sterling, Rubin (2017) illustrates how the development of surgical technologies augmented the policing of the intersex body. Accordingly, the intersexed body perceived as an anatomical pathology became a "correctable" health "disorder" (p. 58). Similarly, Kessler (1990) seeks to establish the genealogical relation between intersex and sex/gender distinction. She extensively examined the medical literature on intersex, especially on infants born with intersex traits and stated the oddity where the "nonnormative is converted in to the normative, and the normative state is considered as natural" (Kessler, 1990, p. 24).

Treading on the gender and biomedical discourse, this paper undertakes Dutee Chand's case study to unpack the confounding and competing claims of the medico-legal recourse. The first section lays out the overview of the arbitrary nature of athletics sex testing trajectory. The second section involves the close reading of the medicalisation of intesex athletes based on the a priori socio-cultural tenet of sex and gender dimorphism. The last section, centring around the exposition of legal inconsistencies found in Dutee Chand's hyperandrogenism trial offers twofold analysis- one being her resolve against all odds to fight for the body she was born with and secondly, it underpins systemic ideology of racism found in the regulatory gaze of the Global North sports bodies.

\section{Theorising Intersex and Mapping Sex Testing}

Sex testing trajectory in sports has a long sordid history. These tests for 'sex', 'gender' and 'femininity', were carried out on athletes to satisfy competing and often contradictory demands from sports organising bodies, scientific professionals, advocacy groups and the athletes themselves. The instances of recorded gender ambiguity in track and field sports goes back to the 1936 Berlin Olympics, when a Polish and American sprinter, Stella Walsh and Helen Stephens's extraordinary athletic feats were put under scanner. Even the outright charge of gender fraud in the case of German athlete, Heinrich Retjen, born with ambiguous genitals in 1938, has had a chequered trail. Disclosure came that Nazi officials pressured Retjen to pose as a woman. It became another acute case of "gender confusion at birth and an ongoing inability to negotiate a new sexual or gender identity" (Heggie, 2014, p. 132). The athletic corporeality, thus, juggled 
between two competing claims- one being the clinical and surgical attempts to restore the "true sex", and the other being its multifaceted nature as suggested by the gender theorists.

Broadly, as a matter of embodied difference, intersex as a concept interrogates the meaning and materiality of sex, gender and sexuality. At a definitional level, it defies any characterization. It does suffer from the "entrenched gendered and sexed ways of knowing" (Rubin, 2017, p. 51). The biomedical standpoint espouses a medical fix towards individual with intersex conditions. Intersex is an umbrella term for people born with "sexual anatomies that societies deem to be nonstandard" (Butler, 2004, p. 65). Dwelling on the idea of prefix inter, Butler marked these as "between the sexes", which resided within "the interstices" of "binary relation" (Butler, 2004, p. 65). The term disorder of sex development (DSD), though rechristened from intersex as all-inclusive clinical category, is still fraught with regressive pattern. The semantic shift stigmatises and "repathologizes" a condition that "should not have been pathologized" and tends to "reinforce a gender binary model" (Breu, 2014, p. 205). The shift in the nomenclature can be better perceived as "medico scientific attempt to pin meanings and bodies down and to control and obscure the uncertainties about embodiments that intersex bodies expose" (Rubin, 2017, p. 19). Rubin (2017) evinces a radical Intersex intervention which is aimed at disrupting the binary schema of sex and gender and ruptures the cultural and biological frames of perception. The intersexual embodiment is built on from Foucault's critique premised on the disciplinary production of modern subject through the notion of sex positioned "in an artificial unity, anatomical elements, biological functions, conducts, sensations and pleasures... and thus able to function as a unique signifier and as a universal signified" (Foucault, 1980, p.154). Extending the discursive framework, Butler opines that sexuality is a "historically specific organization of power, discourse, bodies, and affectivity", where Foucault perceives the production of sex "as an artificial concept which effectively extends and disguises the power relations responsible for its genesis" (Butler, 1990, p. 117).

The idea is not to deny the body as a biological entity but to critically investigate the disciplinary discursivity of bioscience which is to be perceived as a transcendental truth. Etymologically, constituted of bios and logos, the term biology inherently indicates epistemological and technological determination of life. Sterling's critical reading of the history of biological science reveals that "labelling someone male or a woman is a social decision", while stressing that one may adhere to "scientific knowledge to help us make the decision, but only our beliefs about gender-not science, can define our sex" (Fausto-Sterling, 2000, p.3). She stresses to reconsider the mutually constitutive paradigm where genitals only become the qualifying agent of gender or sex along with its medically contended anatomical morphologies. For FaustoSterling (2000), biological traits like chromosomes, hormones and genes are not immaterial constituents but the cultural materiality of the same is not bereft of ideological overdeterminism. These factor in through analysing how "daily lives experiments, and medical practices- scientists create truth about human sexuality; how our body incorporates and confirm these truths...which in turn refashion our cultural environment" (Fausto-Sterling, 2000, p.5). Her critical reading of biomedical research attends to the pathological condition of the intersex.

The IOC justifies the set of sex tests (physiological, genital, hormonal or chromosomal) in the name of fair play, "an ethically complicated aim" (Heggie, 2014, p. 140) owing to the implicit difference in athletic abilities. The 1966 British Empire and Commonwealth games at Kingston, 
Jamaica witnessed IAAF's first calibrated pre-competition sex verification through gynaecological process. The undergone experience by one of the contestants was recounted as the "most crude and degrading experience I have ever known in my life" (Peters and Woolbridge 1974, 55-56). Similarly, later that year, it turned more debasing and invasive when the regulatory authorities at the European Athletic Championship in Hungary, mandated competitor's "nude parade" for anatomical verification ('Preserving la Difference', 1966). The sagacity of the contentious process was avowed by the then IAAF President, David Burghley as an effective measure in "frightening the doubtful ones away" (Pieper, 2016, p. 54).

In their relentless attempts at demarcating male and female categorisation, and to ward off the ignominy of earlier manual tests, the authorities at Unites States Olympic committee initiated a form of non- invasive, swab or hair sampled sex chromatin test, better known as The Barr Body Test. The proxy chromosomal test is credited to the Canadian microanatomist, Murray Barr, who based his assumptions on the difference of dark neurons, distinctly present in female cats (a typical female XX chromosome in humans) than in their male counterparts (Harper, 2019, p. 57). Anything other than $X X$, was literally barred from participation. The physicians tasked with testing at the committee hailed it as "a new definition of femaleness in sport" (Schultz, 2021, p.5). The process in the meanwhile drew geneticist's flak, highlighting its shortcomings and efficacy: ". .. concerning the contribution of various factors (genetic, gonadal, hormonal) towards the sexual identity of an individual ... the presence of an extra chromosome ... cannot be used as indicators of true sex" (Heggie, 2014, p. 138). Owing to the periodic challenge to such testing regimes both from the athletes, activists and scientific fraternity, IAAF in the early nineties dropped its regular testing protocols only with a caveat that if "there is any 'suspicion' or if there is a 'challenge' then the athlete concerned can be asked to attend a medical evaluation before a panel comprising gynecologist, endocrinologist, psychologist, internal medicine specialist, expert on gender/transgender issues" (IAAF, 2006).

Following the vicissitudes of the provision in the coming years, many other athletes fell prey to its predatory medico- juridical trials. IAAF's reclaimed policy to protect the dignity and privacy of individual athletes fell through. In the events of suspicion and scrutiny following the 2006, Asian Games held at Doha, Qatar, Members of the Indian Olympic Association stripped Santhi Soundarajan of her silver medal, stating, she had been "disqualified as per the recommendations of the medical committee on a Games rule violation" ("The sad story of India's Santhi Soundarajan," 2007). Testing trauma led her to attempt suicide. Likewise, South African speedster, Caster Semenya's $800 \mathrm{~m}$ gold with "eight seconds in less than nine months and "strong physical traits" , was ordered to undergo gender verification at Berlin World Championship in 2009 (Koshie, 2019). The then IAAF Secretary, Pierre Weiss' pronouncement: "It is clear that she is a woman but may be not 100 percent" depicts how little the verification discourse had evolved (Semenya, 2009). Subsequently, the IAAF and IOC developed Hyperandrogenism Regulations in 2011, following the mishandling of Semenya's case.

The new regulations defined endogenous testosterone in women's athletic bodies as the touchstone to determine their athletic abilities (IAAF, 2011, p.1). They justified this regulation by maintaining that women with endogenous testosterone get an undue advantage from having masculine physiology, although, they are not technically cheating. Hyperandrogenism is known as the condition where androgenic hormones (testosterones) are produced in excess in women's 
bodies. The regulations set "excessive as 10 or more $\mathrm{nmol} / \mathrm{L}$ of functional testosterone - above the 'normal' reference range for healthy adult women and at the low end for healthy adult men" (Schultz, 2021, p. 8). The IAAF's 2011 regulation unnecessarily pathologized hyperandrogenism and provided two harsh options for women: either to drop out of sport or to agree to the prescribed medical treatment so as to correct their disorder.

\section{Dutee Chand's Deterministic Deviancy}

Dutee Chand became the victim of formal hyperandrogenism regulations. In 2014, she saw meteoric rise when at the age of sixteen, she became the national under-eighteen champion in the 100 meters. She won two gold medals at the Asian Junior Championships, but these victories came at a high cost. Sensing that Chand was too masculine, an unnamed source requested that a hyperandrogenism test be performed on the Indian sprinter. The Athletics Federation of India (AFI) requested for the medical tests to be performed on her. Following which, the Indian sport governing body, the Sports Authority of India (SAI), investigated her case by conducting blood tests and an MRI scan to determine her internal anatomy (Macur, 2014). Chand's testosterone level was deemed by the AFI to be too high to allow her to continue competing in the women's division. She had already been selected to run in the Commonwealth Games but was dropped from the team (Harper, 2019, p.176). In 2014, she was disqualified from international track-andfield events as her body had a higher amount of naturally occurring testosterone. Subsequently, in 2015, when she challenged these rules before the International Court of Arbitration for Sport (CAS), the adjudging panel suspended these regulations for two years citing lack of scientific research and endorsed further dig. Dutee Chand's appeal brought forth the institutional mechanisms that reinforce "the stubborn persistence of binary and biological epistemologies of sex and gender." (Pape 2)

In 2015, Dutee Chand appealed against the regulations at the Court of Arbitration for Sport. She claimed that the Hyperandrogenism Regulations of the sports governing bodies "violated the Olympic Charter's anti-discrimination provisions and international human rights law." (Schultz, p.8) Her legal team argued through expert witnesses that there are significantly two "factual premises" of these regulations which are oversimplified and hence flawed. The first being, that the elevated endogenous testosterone guarantees enhanced performance and second, that medical science can provide separate ranges for male and female athletes. (CAS, 2015, p. 34) The arbitrators stated in the judgement that the IAAF had not backed its regulations with relevant scientific study and opined that "there is presently insufficient evidence about the degree of the advantage that androgen-sensitive hyperandrogenic females enjoy over non-hyperandrogenic females" (CAS, 2015, p.155). Though the panel did not explicitly endorse her claim but maintained that the IAAF had fallen short of the scientific data to support the regulations that affected her. Consequently, they granted the federation two years to produce the evidence or else quash the policy. This judgement paved way for Chand and other intersex sportspersons to compete without undergoing any medical intervention at 2016 Olympic Games in Rio and subsequently at 2021 Tokyo Olympics.

The precarious nature of the judgement foregrounds the medico-legal ethos of intersex. These are conditioned by the conventional distinction that sex is biological comprising of genital, 
hormonal, chromosomal and gonadal traits. The sex and gender dimorphic schema identify male with masculine attributes and female with feminine imputes. Intersex bodies are thus perceived as disordered and overdetermined or "not natural" (Karkazis, 2008, p.11). They become as Rubin (2017), states, "the key others against which hegemonic notions of dimorphic sex and binary gender have been defined" (p. 23). The successive politics of such an understanding as a task of geneology involves "history's destruction of the body" (Foucault, 1991, p.83). Over the course of the twentieth and early twenty first century, the intersex athletes' subjection to the medicojuridical regimes called attention to material-semiotic overdetermination of intersex. Rubin (2017) critiques the "medicalization of intersex" (p. 15) and extends the usage of the term to address the problematics of perception where "treatment of human problem of the politics of difference" is defined as issues that can be dealt exclusively by "medical study, diagnosis and treatment" (p. 15). In the spirit of the argument, the case study precisely tends to "reproduce than resolve, a vast array of inequalities" (p. 15).

\section{Territorializing Deviance}

While defending her case, Dutee Chand's legal team argued that Chand had been born and raised female and should be allowed to compete with other women. Rather than suggest that gender identity should be the most important factor determining eligibility for women's sport, they were claiming that intersex athletes should be allowed to compete with "the body they were born with" (Macur, 2014). This notion that one is "born female" relies on a superficial examination of external genitalia at birth (Macur, 2014). Dr. Payoshni Mitra, an influential Indian activist and academician who has worked on intersex athletes, advised Chand against consenting to either surgery or drugs, but instead, suggested mounting a challenge to the current rules. Mitra vociferously dismisses "normalization" surgery or any medical intervention and opines that "surgery is required only when one has a disease or life-threatening medical condition. Not when one is different" (Embodied, 2014). For her, "the most ideal course of action . . . is to have no course of action at all" (Embodied, 2014). In a similar vein, Kessler substantiates the optimal gender paradigm through her significant review of the 1990's medical practice concerning the surgical normalization of the infants born with non-normative sexual anatomies. She disapproves of the "standard practice for managing intersexuality" by the medical practitioners based on "the cultural understanding of gender" (Kessler, 1990, p.4).

The post 1990's feminist intervention makes a theoretical headway to examine the defective social construct when sex is perceived as the basis of gender. In other words, "gender ought not to be conceived merely as a cultural inscription of a meaning on a pregiven sex (a juridical conception); gender must also designate the very apparatus of production whereby the sexes themselves are established" (Butler, 1990, p.7). The post 1990's activist credo fostered by Intersex Society of North America (INSA) challenging the clinical appropriation, suggest at the significant turn in approach. It states: "intersex is primarily a problem of stigma and trauma, not gender" (Rubin, 2017, 24). Most significantly, INSA's claim gesture at the intersex narrative as the haunting tales about, "shame, secrecy, and unwanted genital surgeries" coupled with unrelenting episodes about "stigma and trauma" (Moorland, 2011, p. 156-157). 
Katrina Karkazis, an American bioethicist and activist, joined forces with Mitra and advised Chand to compete without submitting to any medical procedures. Bruce Kidd, Canadian athlete cum academic, became a third member of their crusade, and they called in to question the androgen-based rules of the IAAF and the IOC. In addition to all the press Karkazis and her colleagues generated, they also secured some impressive legal representation: On September 26, 2014, Jim Bunng, a Canadian lawyer with experience in sports-related cases, filed an appeal with the Court of Arbitration for Sport (CAS) challenging the IAAF's androgen-based rules on Chand's behalf (Sengupta, 2014). On their advice, Dutee Chand refused to give in to the regulations imposed. After Dutee's initial willingness to be "cured" of her intersex state in order to return to sport, she retorted back: "I am what I am" and "it is wrong to have to change your body for sports participation" (Macur, 2014). Furthermore, she argued: "The high androgen level produced by my body is natural. I have not doped or cheated" (Sudai, 2017). Articulating the expert advisors' claim, she exclaimed how the medical treatment to lower androgen levels was "unscientific", "invasive", "often irreversible and will harm my health now and into the future" (Court of Arbitration for Sport, 2015). The legal team, thus, openly challenged the scientific validity of using testosterone as the sole determinant of eligibility for women's sport. Karkazis and other advocates presented the research findings to establish that the advantage of exogenously administered testosterone, which is technically doping, was not applicable to those with higher levels of endogenously produced testosterone (Naimark, 2014). Further, an implicitly prejudiced testosterone profiling was brought to the fore by the Chand's team. This involved placing an upper limit on women's T levels without a corresponding limit on men's T levels was inherently discriminatory (Fagan, 2014). At another level, they bewailed the intense physical and psychological trauma borne out of such surgical interventions. The sports governing policies "takes superbly healthy women and makes them sick, all in the name of ensuring 'fairness'." (Naimark, 2014). Citing these reasons, Dutee Chand appealed against her disqualification from elite track sports in CAS.

Conferring an unfair competitive advantage, athletes with DSDs are subjected to rigorous performance regulatory provisions. These subaltern athletes are made to undergo biomedical diagnosis, which is likely to be gonadectomy, a surgical removal of testes. This in extreme is clinically appended with "a partial clitoridectomy . . . followed by a deferred feminizing vaginoplasty and oestrogen replacement therapy" (Fénichel et al. 2013). Critiquing the conflicting assumptions of level playing field concerning women with DSDs, Karkazis et al. (2012) interrogates "does endogenous testosterone actually confer athletic advantage in a predictable way . . .? and "If there is an advantage from a naturally occurring high testosterone, is that advantage unfair? (p.4) Moreover, her assertions outline that these are driven less by fairness but by inherently asymmetrical "standard protocol in the Global South." (Karkazis and Young, 2018, p. 21). Dutee Chand, like other "suspect" intersex athletes had to undergo medical interventions under the IAAF's regulatory policies which lead to detrimental consequences. Chand was made to undergo intrusive medical interventions without "informed" consent:

She was subjected to a "humiliating" examination by a male doctor, who asked intrusive questions about her body hair, menstrual cycle, surgical history and her hobbies. Several doctors carried out physical examinations of the Athlete body, including on her genital area. The Athlete said she felt vulnerable and did not feel that she had any choice in relation to the testing. (CAS, 2015, p. 108) 
Karkazis (2012, p.13) critiqued the normative basis of these hyperandrogenism regulations which included "deep voice, breast atrophy . . . increased muscle mass, body hair of male type" and argued that these are "entangled with deeply subjective and stereotypical Western definitions of femininity." (CAS, 2015, p.76) These corrective clinical interventions, as Karkazis and Jordan-Young (2018, p. 21) assert aim to bring women from Global South in line with the conventional notions of gender and sexuality acceptable in the Global North. The implication is that the "scientific and popular modes of representing bodies are never innocent but always tie bodies to larger systems of knowledge production and indeed to social and material inequality." (Karkazis and JordanYoung, 2018, p.3) The medical science and popular perceptions are entangled in such a way that suggests their seemingly intersection and how they draw power and authority from each other. Terry and Urla (1995) postulate "the somatic territorializing of deviance" in both medical and popular accounts of "proper" and "improper" bodies. The somatic territorialization is defined as the tendency to "organise social relations according to categories denoting normality versus aberration, health and pathology, and national security versus social danger" (p. 1). The epistemological force of normative propels the fear of deviance as subversive, transgressive and pathologised. Knowledge and discourse work within the framework of binary oppositions and hence construct corporeality in historically and culturally specific ways.

Alcoff (2001) in her article "Towards a Phenomenology of Racial Embodiment" interrogates the ways in which certain bodies are "read and positioned as 'Other' based on their 'visible' nonwhite bodily markers (p. 268). Similarly, this argument can be used to substantiate Dutee Chand's selective geopolitical appropriation. Relevant recourse here is Foucault's (1980) notion of biopolitics, enunciating the convergence of living with techniques of controlling bodies and populations manifesting through socio-cultural institutions like government, legal, economic and healthcare systems. Henne and Pape (2018), Karkazis and Jordan-Young (2018), note that these regulations seem to "disproportionately target women of colour from the Global South" (Pape, p.5), implicating how "the geopolitics of race and nation also shape the constructions of femininity that are privileged in international sport" (p.5). The policies have been consistent with targeting "Black women as suspect in their embodiment of femininity" (Henne and Pape, 2018, p. 218). Such accusations and analysis abound deep rooted racism of Western biomedicine. (Nyong'o 2010; Hoad 2010; Munro 2010; Cooky, Dycus, and Dworkin 2013; Dworkin, Swarr, and Cooky 2013). Zine Magubane's (2014, p. 768) argues for the exposition of the long-standing strain depicting how race and imperial history have played a significant role in constituting intersex. Jacqueline Urla and Jennifer Terry (1995) in their article "Mapping Embodied deviance", notes how the medical discourse acts as a legitimising force in marginalising bodies of difference, and strongly propagates heteronormative bodies.

In other words, perception emerges as more a discursive effect and not as a purely biological one. Alcoff (2001) connotes, "Our experience of habitual perceptions is so attenuated as to skip the stage of conscious interpretation and intent" (p.276). When an intersex body is perceived, it is coloured accordingly with the "tacit bodily knowledges" ( $p .272$ ) that provide a background for perception. These bodily knowledges are tacit by virtue of being "unspoken, habitual, and are therefore difficult to analyse, and yet a discussion of this 'knowingness' about certain kinds of bodies is imperative, and deserves critical attention, precisely because these knowledges inform and shape our interactions, and provide an insight into why we constitute 
some bodies as pathological, regard others as normative" (Murray, 2007, p. 363). The same kind of tacit body knowledge is at work in reading pathologised intersex sports bodies. Intersex as an identity hints at the nebulous bounds of the linguistic and cultural turn models to engage with intersex embodiments as narratives of body that defies reductive sex and gender dualism. Ian Moorland succinctly captures it by stating: "The ethical way to treat intersexed individuals is to preserve, rather than surgically abolish, the uncertainties their bodies provoke" (Moorland, 2006, p.331). Dutee Chand's case and her unprecedented resolve speculates the dire need for bioethical registers which go beyond the medico- legal scrutiny.

\section{Conclusion}

The medico-juridical reading of the atypical athletic body traced out in this paper unravels the ongoing tension between the progressive proponents of gender activists and the scientific-legal custodians of the athletic governing bodies. Critical forays lay bare the problematics of the clinical gaze in the process of the natural selection of the athletic body which is loaded with cultural meanings, specificities and implicit prejudices. Significantly, it depicts how these are not divorced from the hegemonic knowledge that structures the way the sports authorities envision the exclusive idea of fair play. Detailed standpoint analysis of Dutee Chand's case ranging from the charges of deviancy trial to her relentless resolve against the normative regime, radically upends and exposes the selective tradition of the authorities. Lastly, Dutee's confront, on the one hand, highlights the liberating ethos of acknowledging identity in difference and on the other, calls for the ethical envisioning of the slanted gendered athletic trails.

\section{References:}

Alcoff, L. M. (2001). Toward a phenomenology of racial embodiment. In R. Bernasconi (Ed.), Race Malden, MA: Blackwell Publishers. (267-283).

Breau, C. (2014). Insistence of the Material: Literature in the Age of Biopolitics. University of Minnesota Press.

Butler, J. (1990). Gender Trouble: feminism and subversion of Identity. New York: Routledge.

Butler, J. (2004). Undoing Gender. Routledge.

Court of Arbitration for Sport (CAS) (2015) CAS 2014/A/3759 Dutee Chand v. Athletics Federation of India (AFI) \& The International Association of Athletics Federations (IAAF). Lausanne: Court of Arbitration for Sport

Embodied. (2014). Kindle. http://kindlemag.in/embodied/

Fagan, K. (2014). "Fair? The IOC's Gender Testing Policy is the Exact Opposite"

https://www.espn.com/espnw/news-commentary/story/_/id/11494007/fair-ioc-gender-testing-policyexact-opposite

Fausto-Sterling, A. (1992). Myths of gender: biological theories about women and men. New York: Basic Books. 
Fausto-Sterling, A. (2000). Sexing the Body: Gender Politics and the Construction of Sexuality. Basic Books.

Foucault, M. (1980). The History of Sexuality. Volume I: An Introduction, (Robert Hurley, Trans.). New York: Vintage

Foucault, M. (1991). 'Nietzsche, Genealogy, History'. In Paul Rabinow (Ed.), The Foucault Reader, London: Penguin. (83).

Foucault, M. (2003). The birth of the clinic: An archaeology of medical perception, (A. M. Sheridan. Trans.). London: Routledge.

Harper, J. (2019). Sporting Gender: The History, Science, and Stories of Transgender and Intersex Athletes. Rowman and Littlefield.

Heggie, V. (2014). Subjective sex; science, medicine and sex tests in sports. Hargreaves \& Anderson,(Eds.). Routledge Handbook of Sport, Gender and Sexuality (Routledge), 339-347.

"IAAF Policy on Gender Verification." (2006). International Association of Athletics Federation. https://ihra.org.au/wpcontent/uploads/2009/01/iaaf policy on gender verification.pdf

Karkazis, K. (2008). Fixing Sex: Intersex, Medical Authority, and Lived Experience. Duke University Press.

Karkazis, K. et al. (2012) "Out of bounds? A critique of the new policies on hyperandrogenism in elite female athletes" The American Journal Of Bioethics. 12:7, 3-16.

Karkazis, K. \& Jordan-Young, R. (2018). The Powers of Testosterone: Obscuring Race and Regional Bias in the Regulation of Women Athletes. Feminist Formations. 30. 10.1353/ff.2018.0017.

Kessler, S. J. (1990). "The Medical Construction of Gender: case management of Intersexed Infants", Signs. 16:1, 33-38.

Koshie, N. (2019). Caster Semenya's case is about gender, science \& fair play. The Indian Express.

https://indianexpress.com/article/sports/sport-others/caster-semenya-cas-gender-testosterone-athleticsdoping-5588598/

Macur, J. (2014) "Fighting for the Body She was Born with," New York Times https://www.nytimes.com/2014/10/07/sports/sprinter-dutee-chand-fights-ban-over-hertestosterone-level.html

Moorland, I. (2006). Postmodern Intersex. Sytsma S. (Ed.). Ethics and Intersex. International Library of Ethics, Law and the New Medicine, 29. Springer, Dordrecht. https://doi.org/10.1007/1-4220-43147_20

Moorland, I. (2011). "Intersex Treatment and the Promise of Trauma". Gender and science of Difference: Cultural Politics of Contemporary Science and Medicine. Jill Fisher (Ed.). New Brunswick: Rutgers University Press.

Naimark, M. (Sep, 2014). Slate. https://slate.com/human-interest/2014/09/sex-verification-in-sports-anew-study-supports-unfairly-excluded-female-athletes.html

Pape, Madeleine. (2019) "Expertise and Nonbinary Bodies: Sex, Gender and the Case of Dutee Chand" Body and Society,XX(X),1-26.

Rubin, D. A. (2017). Intersex Matters: Biomedical Embodiment, Gender Regulation, and Transnational Activism. Albany: State University of New York Press (SUNY). 224.

Rupert, J (2011). The History and Biology of Gender Verification in the Olympics. https://www.utpjournals.press/doi/pdf/10.3138/cbmh.28.2.339 
13 Atypical Athletic Corporeality and Clinical Embodied Deviance: A Case Study of Dutee Chand

Samantha, M. (2007). Corporeal Knowledges and Deviant Bodies: Perceiving the Fat Body, Social Semiotics, 17:3, 361-373. DOI: 10.1080/10350330701448694

Schultz, Jaime. (2019). Good enough? The 'wicked' use of testosterone for defining femaleness in women's sport. Sport in Society, 24, 1-21. 10.1080/17430437.2019.1703684.

Semenya 'maybe not 100pc' a woman. (2009, September, 11). ABC News.

https://www.abc.net.au/news/2009-09-11/semenya-maybe-not-100pc-a-woman/1424994

Sudai M. (2017). The testosterone rule-constructing fairness in professional sport. Journal of law and the biosciences, 4(1), 181-193. https://doi.org/10.1093/jlb/lsx004

"The sad story of India's Santhi Soundarajan." (2007, October 1). China Daily. http://www.chinadaily.com.cn/sports/2007-01/10/content_779666.htm

Urla, J., and Terry, J. (1995). Introduction: Mapping embodied deviance. In J. Terry and J. Urla (Eds.). Deviant bodies: Critical perspectives on difference in science and popular culture, Bloomington: Indiana University Press. (1-18).

Young, L.M., and Powell, B. (1985). The effects of obesity on the clinical judgements of mental health professionals. Journal of Health and Social Behaviour, 26, 233-246.

${ }^{1}$ Isha Malhotra (Ph.D., University of Jammu, India, 2019) is an Assistant Professor and Head in the School of Languages and Literature, Faculty of Humanities and Social Sciences at Shri Mata Vaishno Devi University, UT of J\&K, India. Her research interests include cultural studies with specific focus on gender, neoliberalism and biopolitics. Email: isha.malhotra@smvdu.ac.in

${ }^{2}$ Raj Thakur (Ph.D., Panjab University, India, 2017) is an Assistant Professor in the Department of English at Central University of Jammu, UT of J\&K, India. His area of interest includes cultural studies, critical theory, popular culture and sports literature. Email: raj.eng@cujammu.ac.in 